\title{
8
}
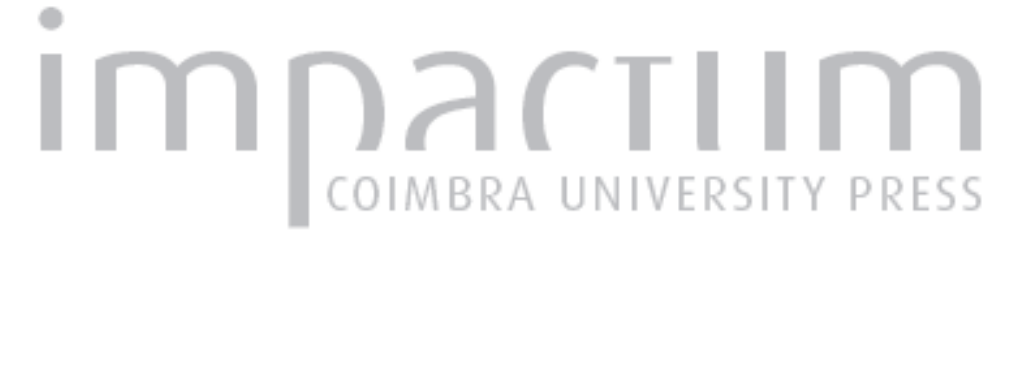

\section{Escorrência e erosão a múltiplas escalas espaciais numa área florestal mista recentemente ardida no Centro de Portugal}

\author{
Autor(es): $\quad$ Fernandes, Isabel A. C.; Nunes, J. P.; Ferreira, Raquel S. V.; Pereira, \\ Luísa M. G. P.; Vieira, Diana C. S.; Keizer, J. J. \\ Publicado por: Associação Portuguesa de Riscos, Prevenção e Segurança \\ URL \\ persistente: \\ URI:http://hdl.handle.net/10316.2/36103 \\ DOI: \\ DOI:http://dx.doi.org/10.14195/1647-7723_17_14 \\ Accessed : $\quad$ 26-Apr-2023 09:58:30
}

A navegação consulta e descarregamento dos títulos inseridos nas Bibliotecas Digitais UC Digitalis, UC Pombalina e UC Impactum, pressupõem a aceitação plena e sem reservas dos Termos e Condições de Uso destas Bibliotecas Digitais, disponíveis em https://digitalis.uc.pt/pt-pt/termos.

Conforme exposto nos referidos Termos e Condições de Uso, o descarregamento de títulos de acesso restrito requer uma licença válida de autorização devendo o utilizador aceder ao(s) documento(s) a partir de um endereço de IP da instituição detentora da supramencionada licença.

Ao utilizador é apenas permitido o descarregamento para uso pessoal, pelo que o emprego do(s) título(s) descarregado(s) para outro fim, designadamente comercial, carece de autorização do respetivo autor ou editor da obra.

Na medida em que todas as obras da UC Digitalis se encontram protegidas pelo Código do Direito de Autor e Direitos Conexos e demais legislação aplicável, toda a cópia, parcial ou total, deste documento, nos casos em que é legalmente admitida, deverá conter ou fazer-se acompanhar por este aviso. 


\section{territorium}

Riscos, Sociedade(s) e Segurança

Revista da Associação Portuguesa de Riscos, Prevenção e Segurança 2010 

NO CENTRO DE PORTUGAL ${ }^{1 *}$

Isabel A. C. Fernandes*

isabelfernandes@ua.pt

J. P. Nunes*

jpcn@ua.pt

Raquel S. V. Ferreira *

raquelferreira@ua.pt

Luísa M. G. P. Pereira **

luisapereira@ua.pt

Diana C. S. Vieira

dianac.s.vieira@ua.pt

J. J. Keizer *

jikeizer@ua.pt

* Centro de Estudos do Ambiente e do Mar (CESAM), Departamento de Ambiente e Ordenamento, Univ. de Aveiro ** Escola Superior de Tecnologia e Gestão de Águeda (ESTGA), Universidade de Aveiro

\section{RESUMO}

O presente artigo apresenta resultados preliminares da monitorização de escorrência e erosão do solo após incêndio, numa micro-bacia hidrográfica no centro de Portugal. Os dados recolhidos permitem avaliar os diferentes processos que governam a resposta hidrológica e a erosão a diferentes escalas espaciais, micro parcela $\left(<2 \mathrm{~m}^{2}\right)$, encostas de vários comprimentos (40 a $90 \mathrm{~m}$ ) e micro bacia $\left(11 \times 10^{4} \mathrm{~m}^{2}\right)$.

Palavras-chave: fogos florestais, hidrologia, erosão do solo.

\section{RÉSUMÉ}

Cet article présente les résultats préliminaires de la surveillance du ruissellement et de l'érosion du sol après incendie, dans un micro bassin hydrographique au centre du Portugal. Les données recueillies permettent d'illustrer des différences dans les processus qui gouvernent la réponse hydrologique et l'érosion à différentes échelles spatiales: micro parcelle $\left(<2 \mathrm{~m}^{2}\right)$, flanc de diverses tailles $\left(40\right.$ a $\left.90 \mathrm{~m} \mathrm{~m}^{2}\right)$ et micro bassin $\left(11 \times 104 \mathrm{~m}^{2}\right)$.

Mots-clé: incendie de forêt, hydrologie, érosion du sol.

\section{ABSTRACT}

This article presents preliminary results from the monitoring of post-wildfire surface runoff and soil erosion in a microcatchment in central Portugal. The data illustrate the different processes governing both the hydrological and erosion response at different spatial scales: micro-plot $\left(<2 \mathrm{~m}^{2}\right)$, slopes of varying length $(40 \mathrm{a} 90 \mathrm{~m})$ and for the entire microcatchment $\left(11 \times 10^{4} \mathrm{~m}^{2}\right)$.

Key words: forest fires, hydrology, soil erosion.

$1^{*} \mathrm{O}$ texto deste artigo corresponde à comunicação apresentada ao V Encontro Nacional e I Congresso Internacional de Riscos e foi submetido para revisão em 02-12-2009, tendo sido aceite para publicação em 19-02-2010.

Este artigo é parte integrante da Revista Territorium, n. ${ }^{\circ} 17,2010$, (c) Riscos, ISBN: 0872- 8941. 


\section{Introdução}

De acordo com a revisão bibliográfica detalhada de Shakesby e Doerr (2006), os efeitos negativos dos incêndios florestais incluem efeitos directos, como a destruição do coberto vegetal e alterações no solo, mas também indirectos, nomeadamente um incremento na escorrência e nas perdas de solo associadas. A destruição do coberto vegetal que normalmente dificulta a actuação dos processos erosivos, faz com que a erosão natural das vertentes seja acelerada levando, por vezes, a uma destruição notável dos solos enquanto a cobertura vegetal não se recompõe (e. g. LouRenço, 2004a; KeIZER et al., 2006; Shakesby e Doerr, 2006). Áreas serranas ardidas que apresentavam uma camada delgada de solo antes do incêndio, depois deste ocorrer, poderão apresentar solos esqueléticos ou, por vezes, ficar completamente desprovidas de qualquer tipo de solo, sendo visível a rocha nua que passa a aflorar à superfície $(e . g$. LOURENço, 2004b).

A erosão do solo em áreas florestais ardidas no centro de Portugal tem sido alvo de investigação recente, no âmbito dos projectos EROSFIRE e EROSFIRE II. O projecto EROSFIRE (POCI/AGR/60354/2004) surgiu como consequência dos incêndios florestais ocorridos durante 2003, em Portugal, e da produção do mapa “A erosão do solo após os incêndios florestais do Verão de 2003" pelo Instituto da Água, na sequência desses incêndios. Este mapa foi baseado numa versão modificada da Equação Universal de Perdas de Solo (USLE) que, pelas suas características originais, não se adequa necessariamente às condições pós-fogo e ignora os avanços que nas últimas décadas ocorreram na modelação numérica da erosão do solo. A proposta base do projecto foi a de desenvolver uma ferramenta de modelação para a avaliação do risco de erosão em áreas recentemente ardidas, assente em bases científicas mais inovadores que a USLE.

O projecto EROSFIRE-II (PTDC/AGR-CFL/70968/2006) surge como uma continuação, bem como uma extensão do projecto EROSFIRE. A recolha de dados e o desenvolvimento de ferramentas de modelação estão a ser efectuados para outras áreas geográficas, ou seja, com diferentes características físico-ambientais (por exemplo, precipitação), distintos tipos de cobertura terrestre (especialmente pinhais), diferente gestão do solo após incêndio e/ou intensidades de incêndio mais severas. Por outro lado, o projecto tem intenção de avaliar e prever o risco de erosão após incêndio a diferentes escalas. A análise será efectuada não só ao nível de micro parcelas e encostas individuais, mas também à escala da micro bacia hidrográfica (incluindo os canais e as estradas florestais).

0 presente artigo apresenta alguns resultados preliminares do projecto EROSFIRE II. As respostas hidrológica e da erosão do solo à precipitação têm sido medidas e analisadas desde Setembro de 2008, numa área florestal mista de pinhal e eucaliptal recentemente ardida. As observações foram efectuadas a múltiplas escalas espaciais, através da monitorização de micro parcelas, parcelas abertas, barreiras de sedimentos e um canal hidráulico, permitindo levantar questões importantes sobre a organização espacial destes processos dentro de bacias hidrográficas ardidas, bem como sobre a evolução desta organização com a sucessão das estações do ano e o recobro do coberto vegetal.

\section{Materiais e métodos}

\section{Área de estudo}

Em 27 de Agosto de 2008 ocorreu um incêndio em Góis (fig. 1), na serra da Lousã, que apresentou características de acordo com os critérios inicialmente estipulados para a selecção de uma área de estudo para o projecto EROSFIRE II. Tratou-se de um incêndio com uma área ardida de cerca de 70 ha, cuja parte central corresponde a uma bacia quase totalmente ardida com cerca de 11 ha.

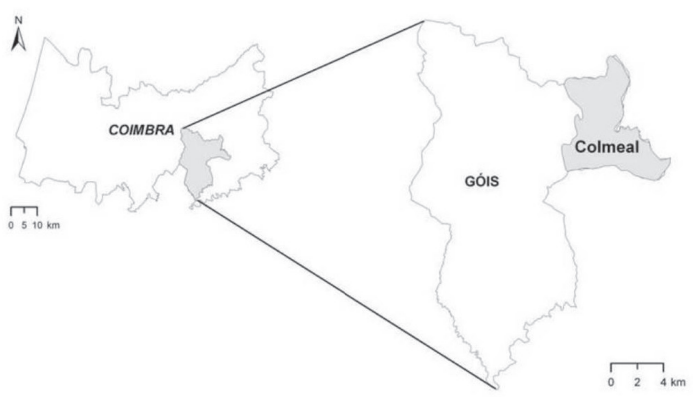

Fig. 1 - Localização geográfica do local de estudo relativamente ao distrito, concelho e freguesia.

A área ardida era maioritariamente coberta por plantações privadas de eucaliptal com o objectivo de comercialização da respectiva madeira (exploração florestal); uma outra parte correspondia a terrenos baldios, cobertos por pinheiros.

A temperatura média anual da área de estudo situa-se entre os 10 e os $12,5^{\circ} \mathrm{C}$, enquanto que a precipitação média anual varia entre os 1400 e os $1600 \mathrm{~mm}$ (Atlas do Ambiente, Instituto do Ambiente, 2008). A descrição de alguns perfis de solo realizados nesta área indicou que o solo predominante é do tipo Cambissolo sobre xisto. 
Monitorização de precipitação, hidrologia e erosão do solo

A instalação dos equipamentos no campo começou 3 semanas após o incêndio. A localização destes equipamentos pode ser visualizada na fig. 2 . humidade, colocados em duas encostas distintas da bacia central, e com vários pluviómetros totalizadores e automáticos (fig. 3).

Em finais de Novembro de 2008, foi instalada uma estação hidrométrica (fig. 4), composta por um canal

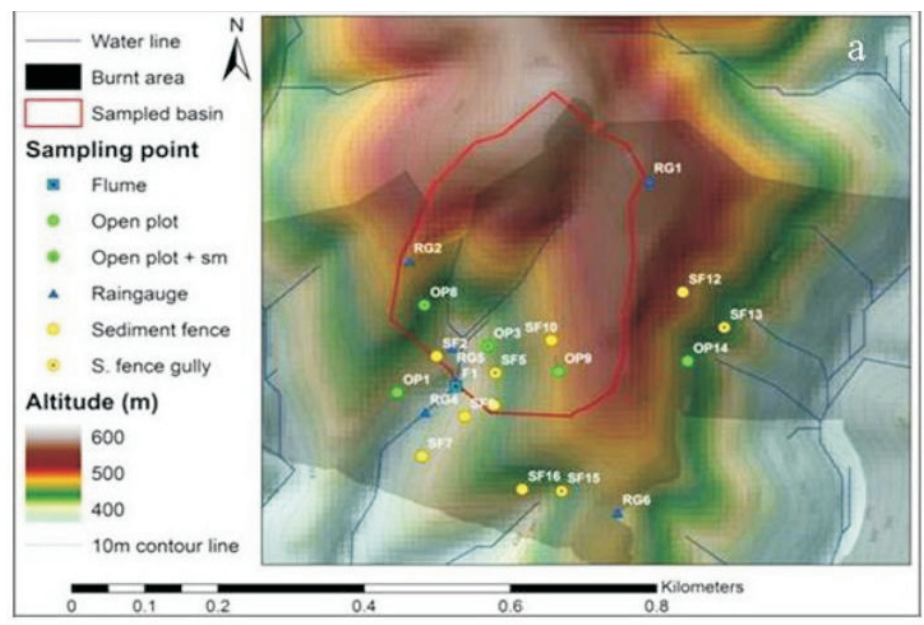

Fig. 2 - a) Pontos de amostragem e altitude da área de estudo;

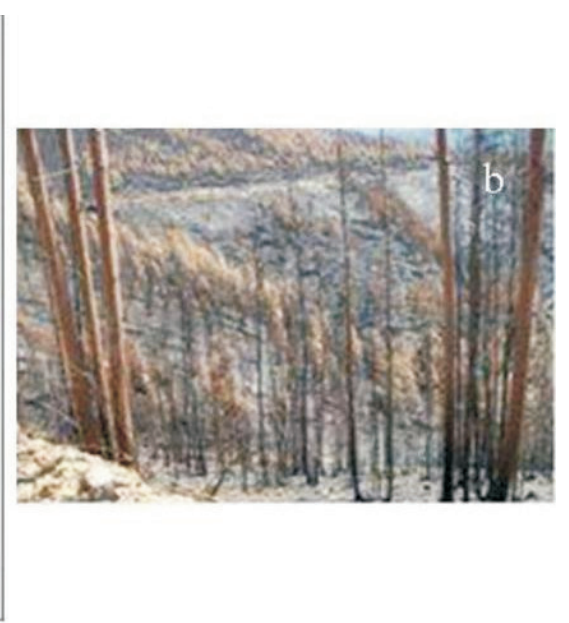

b) fotografia da bacia central.
Para o presente trabalho, foi analisada a escorrência de duas encostas localizadas na bacia central da área de estudo. Cada encosta está equipada com quatro micro parcelas (BP; "bounded plots"), duas com 0,25 $\mathrm{m}^{2} \mathrm{e}$ duas com $0,50 \mathrm{~m}^{2}$, e ainda com quatro parcelas abertas (OP; “open plot"; fig. 2) que totalizam cerca de 2 metros de largura, cuja área de drenagem é superior a $100 \mathrm{~m}^{2}$ (fig. 3). Todas estas parcelas de erosão foram instaladas nas bases das encostas e estão espaçadas por poucos metros. As parcelas estão ligadas a tanques que armazenam a escorrência que semanalmente é medida, caso haja ocorrência de precipitação, e amostrada para análise posterior em laboratório.

$\mathrm{Na}$ área ardida foram instaladas barreiras de sedimentos (SF; "sediment fence"; fig. 2), parte das quais foram colocadas à escala de encosta e as restantes em ravinas e vales. A área foi ainda equipada com sensores de
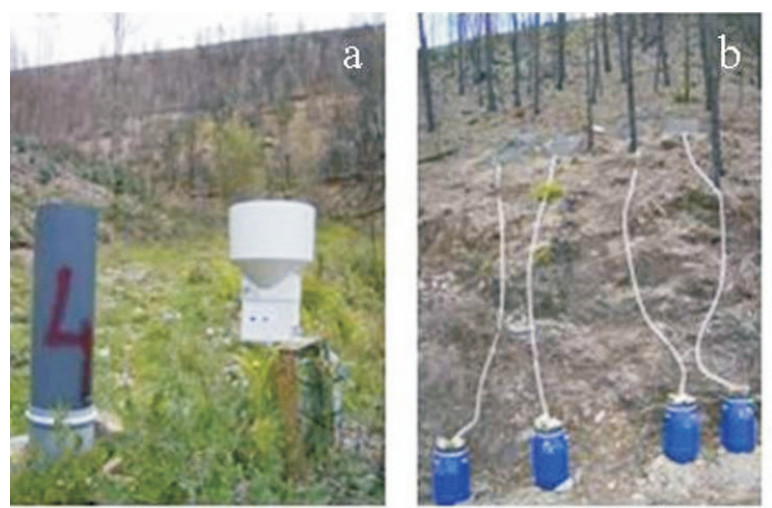

hidráulico, sensores de nível de água e turbidez, e um amostrador automático com capacidade para recolher 24 amostras.

É efectuada regularmente uma descrição do coberto do solo das micro parcelas, através de uma grelha do tamanho das parcelas, subdividida em quadrados de 5 $\mathrm{cm}$ de lado (fig.5). Além desta descrição, são tiradas fotografias de cada parcela.

Foram ainda realizados transectos em cada uma das encostas para caracterização geral das mesmas. Os transectos abrangem uma descrição de indicadores de intensidade do fogo e do coberto do solo. Cada encosta foi dividida em 5 pontos equidistantes e em cada ponto foi efectuada uma descrição, com uma grelha idêntica à usada para a descrição das micro parcelas. Na fig. 6 , pode visualizar-se o aspecto geral de um transecto, assim como um dos seus pontos.
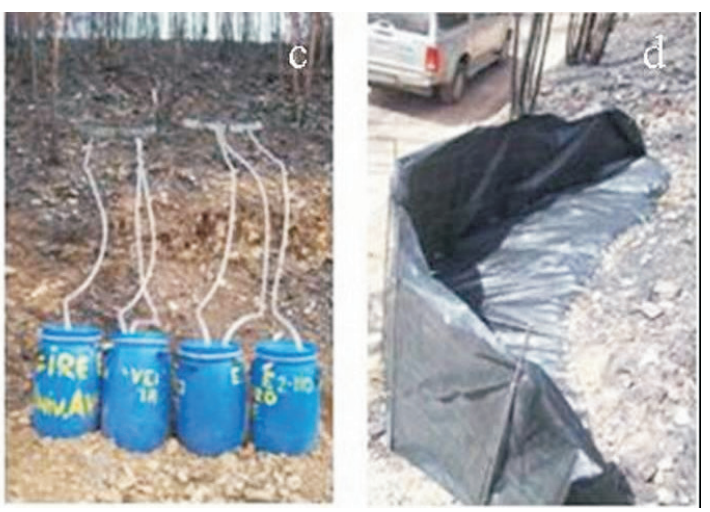

Fig. 3 - a) Pluviómetro totalizador e automático; b) micro parcelas; c) parcelas abertas; d) barreira de sedimentos. 

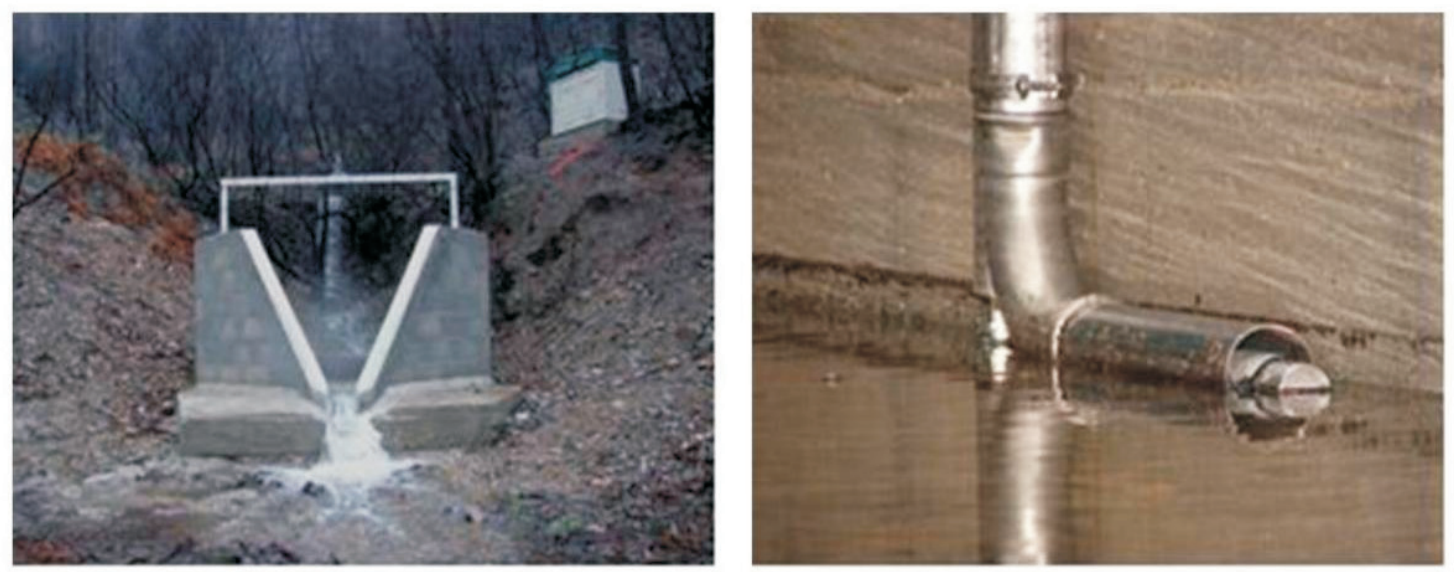

Fig. 4 - Estação hidrométrica.
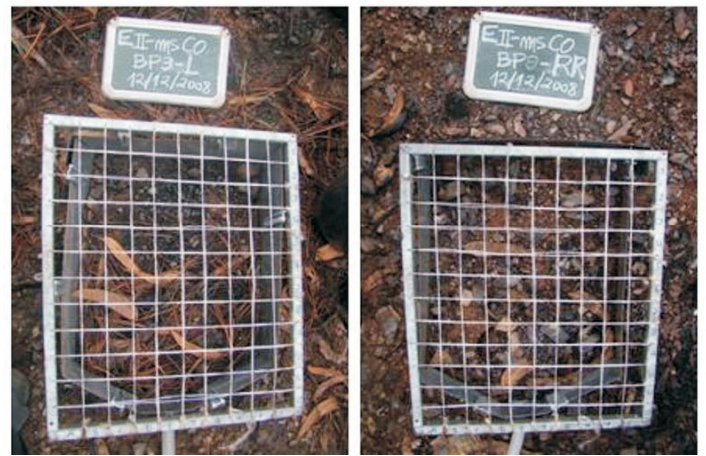

Fig. 5 - Descrição com grelha de micro parcelas das encostas 3 e 8.

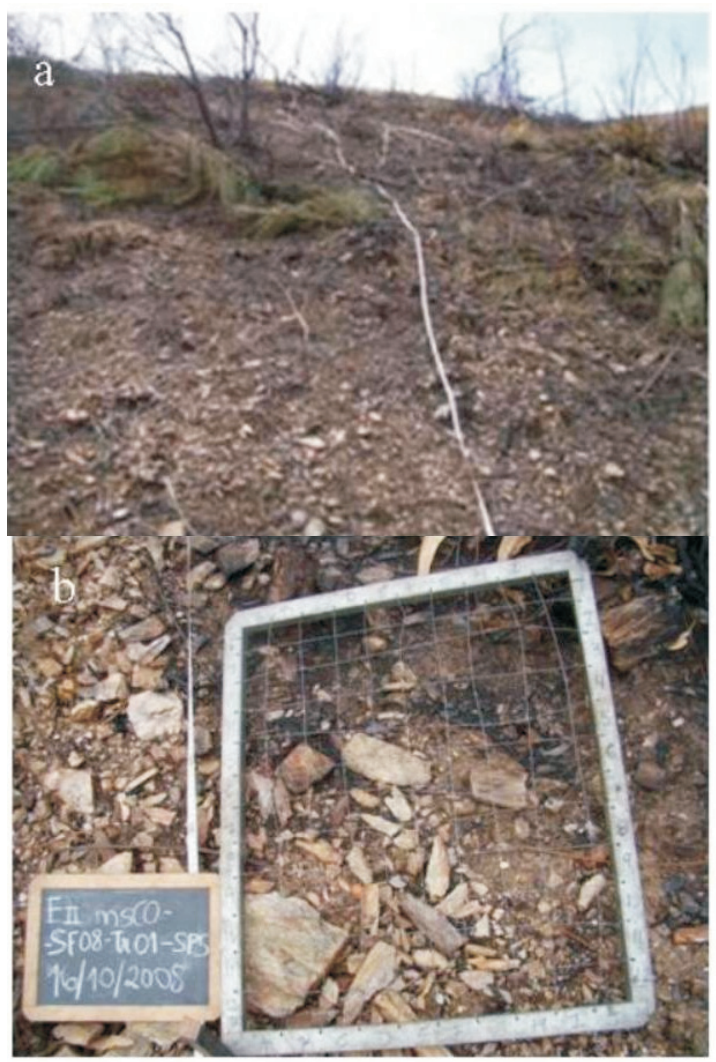

Fig. 6 - a) Aspecto geral de um transecto; b) Ponto do transecto com a grelha de descrição.
No QUADRo I, apresentam-se as características principais das duas encostas utilizadas neste estudo. A encosta 3 tem como coberto principal o Pinus pinaster Ait., enquanto a encosta 8 é coberta por Eucalyptus globulus Labill. As duas encostas têm aproximadamente a mesma inclinação, mas os seus comprimentos são distintos, resultando em áreas de drenagem bastante diferentes ao nível das parcelas abertas.

Quadro I - Características gerais das encostas onde estão instaladas as parcelas.

\begin{tabular}{cccccc|} 
& Coberto & $\begin{array}{c}\text { Inclinação } \\
\left({ }^{\circ}\right)\end{array}$ & $\begin{array}{c}\text { Comprimento } \\
\text { da encosta }(\mathrm{m})\end{array}$ & $\begin{array}{c}\text { Área de } \\
\text { drenagem } \mathrm{BP} / \\
\mathrm{OP}\left(\mathrm{m}^{2}\right)\end{array}$ & Gestão do solo \\
\hline $\begin{array}{c}\text { Encosta } 3 \\
\text { (BP3 / OP3) }\end{array}$ & Pinhal & 27 & 85 & $1,5 / 174$ & lavrado horizontal \\
$\begin{array}{c}\text { Encosta } 8 \\
\text { (BP8 / OP8) }\end{array}$ & Eucaliptal & 29 & 62 & $1,3 / 116$ & lavrado vertical \\
\hline
\end{tabular}

\section{Resultados e discussão}

Os dados recolhidos e analisados correspondem ao período de Setembro a Dezembro de 2008; a precipitação total registada foi aproximadamente de $250 \mathrm{~mm}$. Distinguem-se nesta análise dois períodos fundamentais: os primeiros meses (Setembro, Outubro, Novembro), com cerca de $70 \mathrm{~mm}$ de precipitação, e o mês de Dezembro, com bastante mais precipitação, cerca de $180 \mathrm{~mm}$. Na fig. 7, podem observar-se as escorrências registadas nas parcelas das encostas 3 e 8 em ambos os períodos, assim como a respectiva precipitação.

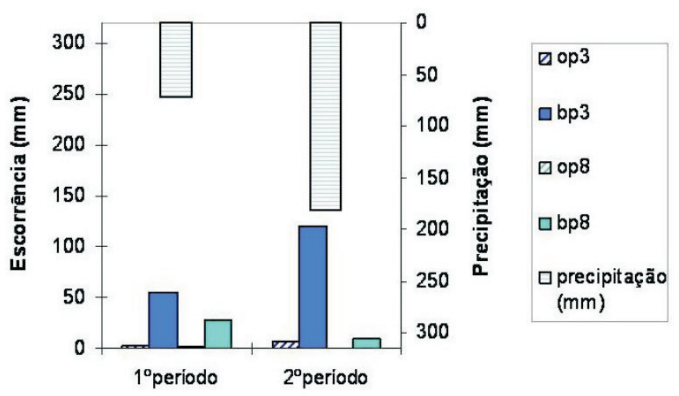

Fig. 7 - Escorrência e precipitação nas parcelas abertas (op) e micro parcelas (bp) 3 e 8. 
A fig. 8 mostra, com mais pormenor, a escorrência e a erosão registadas nas parcelas 3 e 8 durante ambos os períodos de estudo. É possível observar nos dados diferenças substanciais:

- na escorrência e na erosão entre parcelas abertas (menor) e micro parcelas (maior);

- na escorrência e na erosão entre as encostas das parcelas 3 (maior) e 8 (menor);

- na escorrência entre o $1^{\circ}$ e o $2^{\circ}$ período em que, apesar da maior precipitação, a escorrência só aumenta na encosta das parcelas 3; na erosão entre o $1^{\circ}$ e o $2^{\circ}$ período em que diminui, apesar da maior precipitação e, no caso da encosta das parcelas 3 , também maior escorrência.

Estas diferenças serão exploradas nas secções seguintes.

\section{Diferenças entre parcelas abertas e micro parcelas}

Na fig. 8 pode verificar-se que a escorrência por unidade de área nas parcelas abertas é bastante inferior à registada nas micro parcelas; o mesmo se verifica com o coeficiente de escorrência, que é da ordem dos $30 \%$ nas micro parcelas e de apenas $1 \%$ nas parcelas abertas. A erosão do solo por unidade de área segue o mesmo padrão, com média de cerca de $32 \mathrm{~g} / \mathrm{m}^{2}$ nas micro parcelas, nos dois períodos, e apenas $1,9 \mathrm{~g} / \mathrm{m}^{2}$ nas parcelas abertas.

Este fenómeno pode dever-se à grande variabilidade espacial tipicamente observada na geração de escorrência dentro de uma determinada encosta, em especial quando a intensidade e quantidade de precipitação estão abaixo do necessário para a geração de escorrência contínua ao longo da encosta e quando o coberto vegetal é reduzido (e. g. BoIx-Fayos et al., 2006; CAMmeraAt, 2002; KIRKBY et al., 2002). Nestas condições, a conectividade hidrológica (ligação entre áreas de geração de escorrência) entre pontos dentro da encosta e a sua parte mais baixa é reduzida, dado existirem numerosas oportunidades para a escorrência gerada num ponto (neste caso, os dados observados em micro parcelas representam o escorrência pontual), reinfiltrar em partes da encosta mais baixas, por exemplo em macroporos ou zonas de maior capacidade de infiltração,
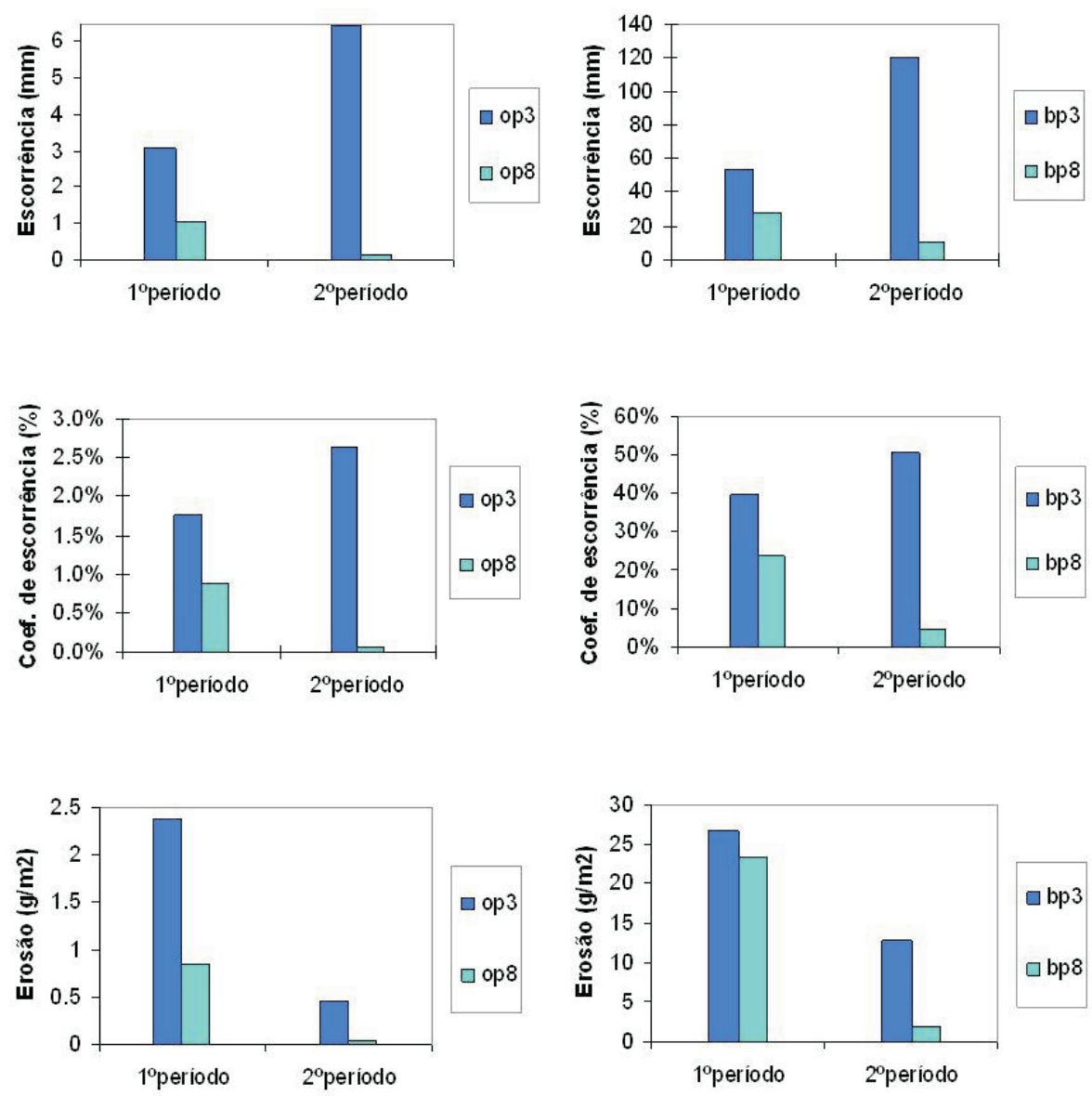

Fig. 8 - Escorrência e erosão nas parcelas abertas (op; esquerda) e micro parcelas (bp; direita) 3 e 8. 
ou ficar retido à superfície em zonas de terreno mais irregular; este fenómeno foi observado em outras bacias hidrográficas em alturas em que a precipitação é baixa e irregular (e. g. Boix-Fayos et al., 2006; CammeraAt, 2002; KirkBy et al., 2002; Parsons et al., 2006; Puigdefabregas et al., 1998; YAIR E RAZ-YASSIF, 2004).

Em áreas ardidas, a presença de repelência à água do solo, bem como a sua elevada variabilidade espacial ( $e$. g. KEIZER et al., 2008) poderá também contribuir para a variabilidade das taxas de infiltração, possivelmente incentivando a redução do coeficiente de escorrência com o aumento da encosta, conforme também proposto por FERREIRA et al. (2008).

Este fenómeno poderá contribuir também para as diferenças de erosão entre micro parcelas e encostas, uma vez que a fraca conectividade hidrológica possui um efeito limitante sobre a conectividade de transporte de sedimentos, e ainda devido à distância mais limitada a que as partículas suspensas na escorrência poderão ser movidas antes de se redepositarem (Boix-Fayos et al., 2006; Cammeraat, 2002; Ferreira et al., 2008; Parsons et al., 2006).

No caso da presente área de estudo, todos estes fenómenos poderão estar a contribuir para a diferença de escorrência e erosão entre micro parcelas e encostas. De qualquer forma, deve-se notar que esta diferença ocorre essencialmente na escorrência e na erosão por unidade de área; a escorrência volumétrica e a massa de solo erodido das encostas foram superiores ao das parcelas fechadas em cerca de uma ordem de grandeza.

\section{Diferenças entre as encostas das parcelas 3 e 8}

Verifica-se também na fig. 8 uma diferença significativa na escorrência e na erosão entre encostas; a encosta das parcelas 3 (encosta mais longa, conforme indicado no Quadro I) apresenta maior escorrência e erosão em ambos os períodos. Esta diferença é mais notável no segundo período, durante o qual a escorrência e a erosão são inferiores em cerca de uma ordem de grandeza.

Uma possível explicação poderá estar no facto de, na encosta onde estão localizadas as parcelas 3 , o solo encontrar-se coberto com folhas de pinheiro, podendo esta cobertura reduzir os valores de infiltração. No entanto, esse aumento poderá ser parcial ou totalmente compensado pelo aumento da capacidade de retenção de escorrência na superfície das próprias folhas. Além disso, este coberto contradiz o aumento de erosão, que seria limitado pela maior protecção dada ao solo pelo coberto.

Outra possível explicação poderá estar no comprimento e área de drenagem nas encostas (conforme indicado no Quadro I). O aumento da área drenada, quando associado à ocorrência de escoamento subsuperficial lateral, levará a que uma maior quantidade desta escorrência se acumule em encostas mais longas; esta acumulação poderá determinar a ocorrência de geração de escorrência por saturação do solo na parte mais baixa de encostas mais longas, conforme se observa também em outras bacias hidrográficas (e. g. Boıx-Fayos et al., 2006; Cammeraat, 2002; Soler et al., 2008). Um indicador da ocorrência deste fenómeno é a humidade relativa medida nas duas encostas; conforme se pode ver na fig. 9 , esta é superior na encosta das parcelas 3, podendo este facto ser causado pela acumulação de escoamento subsuperficial. No entanto, outras explicações poderão ser avançadas, tais como o lavrado horizontal ou a manta protectora de folhas de pinheiro sobre o solo que limitariam a evapotranspiração ou diferenças na repelência à agua dos solos em pinhais e eucaliptais.

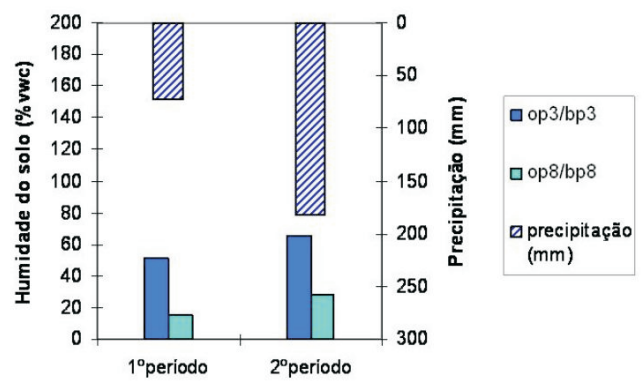

Fig. 9 - Humidade registada nas encostas relativas às parcelas 3 e 8, e precipitação, nos mesmos períodos.

No entanto, a observação de maior escorrência e erosão nas encostas mais compridas é contraditória com o fenómeno da redução do coeficiente de escorrência com o aumento do comprimento das encostas e, portanto, da área das parcelas, discutido na secção anterior. Poderão aqui coexistir os dois fenómenos: a encosta das parcelas 3 poderá ser suficientemente longa para a importância da fraca conectividade hidrológica e a reinfiltração poderá ser contrabalançada, em parte, pelo aumento da humidade do solo e da escorrência por saturação (e consequente erosão). Um indicador desta sobreposição de fenómenos poderá ser o factor de diferença de escorrência entre encostas também se verificar para as micro parcelas; ambas estão localizadas na base das encostas, pelo que a maior humidade relativa registada na parcela 3 também deverá influenciar a maior escorrência nas micro parcelas 3 , relativamente às micro parcelas 8 (fig. 8). Será necessário analisar a escorrência nas restantes encostas (mostradas na fig. 3 ) antes de se poder tirar conclusões mais fortes sobre a importância da escorrência por saturação nas encostas mais longas da área de estudo. 
Diferenças entre o $1^{\circ}$ e o $2^{\circ}$ período

Em relação ao primeiro e segundo período, percebem-se duas situações bastante diferentes (fig. 8). Na encosta das parcelas 3, a escorrência aumenta quando se regista um valor mais elevado de precipitação, enquanto que, na encosta das parcelas 8 , a escorrência diminui no segundo período. Também se verifica uma maior disparidade nos valores do coeficiente de escorrência entre encostas durante o segundo período, quando comparados com o primeiro período.

A variabilidade sazonal da repelência do solo à água poderá fornecer algumas pistas para compreender estas diferenças. As medições de repelências efectuadas na área de estudo ainda não se encontram analisadas; no entanto, em áreas ardidas portuguesas foi observada uma maior repelência durante períodos mais quentes e secos, sendo que esta é quebrada durante períodos de maior precipitação e menor temperatura (e. g. KEIZER et al., 2008). Desta forma, e observando a precipitação medida na fig. 9, poder-se-á esperar uma repelência superior durante o $1^{\circ}$ período (Setembro a Novembro) que durante o $2^{\circ}$ período (Dezembro). A maior humidade do solo durante o $2^{\circ}$ período poderá ser consequência não só da maior precipitação, mas também da menor repelência, sendo que existe geralmente uma relação inversa entre ambos os parâmetros (e. g. KEIZER et al., 2008).

A possível diminuição da repelência entre o primeiro e o segundo período de análise permite avançar uma possível explicação para o comportamento das parcelas em ambos os períodos:

- No primeiro período, a presença de repelência limitaria a infiltração da escorrência (e.g. LEIGHTONBoyce et al., 2007), limitando também o escoamento subsuperficial, e a presença de humidade do solo na encosta das parcelas 3; desta forma, poder-se-iam esperar maiores semelhanças entre as parcelas 3 e 8 , sendo mais importante a geração de escorrência por excesso de infiltração.

- No segundo período, a ausência de repelência levaria à redução de escorrência em encostas mais curtas (representadas pela encosta das parcelas 8), devido ao aumento da infiltração. No entanto, o aumento de infiltração levaria também ao aumento do escoamento subsuperficial e da sua acumulação em encostas mais compridas (representadas pela encosta das parcelas 3), aumentando a geração de escorrência. Este fenómeno podería explicar a redução da escorrência na encosta 8 acompanhada do aumento da escorrência na encosta 3 .

É dificil encontrar dados que suportem a ocorrência destes processos, devido ao facto de nem a repelência, nem a escorrência em outras encostas terem sido analisados; além disso, a falta de outros estudos, a múltiplas escalas espaciais em bacias ardidas, limita a comparabilidade dos presentes resultados. No entanto, um processo semelhante foi proposto por Jung et al. (2009) para explicar a diferença entre fontes de escorrência em bacias ardidas (dominadas por escorrência) e não ardidas (dominadas por escoamento subsuperficial) na Califórnia. Deve-se ainda notar que a transição de um período seco, em que o escoamento é gerado por limitações à infiltração, para um período húmido, em que o escoamento é gerado por excesso de saturação na base de encostas, foi também notado noutras bacias de clima mediterrânico por KIRKBY et al. (2002). Este facto dá alguma credibilidade à explicação apresentada acima, o que indica a utilidade de prosseguir esta linha de análise.

Contrastando com a escorrência, a erosão do solo atinge valores mais elevados no primeiro período, tanto nas micro parcelas como nas parcelas abertas, diminuindo no segundo período em ambas as parcelas apesar do aumento da precipitação e, nas parcelas 3, da escorrência (fig.7). Estes resultados podem ser explicados pela fragilidade da camada superficial do solo depois do incêndio (devido à destruição de agregados), o que tornaria o solo mais vulnerável ao arrasto pela escorrência $(e$. g. ANDREU et al., 2001). No segundo período, não só se esperaria a recuperação destes agregados, bem como a erosão de finos superficiais poderia deixar o solo mais grosseiro e desta forma mais resistente à erosão (SHAKESBY et al., 2002). Desta forma, o aumento da resistência do solo à erosão poderá ter sido suficiente, num curto espaço de tempo, para limitar a capacidade de arrastamento da escorrência. É no entanto difícil sustentar esta conclusão, uma vez que ainda não foram analisadas amostras de solo recolhidas na área de estudo, e poderão existir outros factores tais como a acumulação de camadas de folhas e outros resíduos na base da encosta 3 , arrastadas pela escorrência, ou a recuperação inicial do coberto vegetal durante o final do Outono.

\section{Observações à escala da micro bacia}

Os dados observados no canal hidráulico podem ser observados na fig. 10, para o mês de Dezembro, correspondendo ao $2^{\circ}$ período de observações. Pode-se observar que a escorrência é superior à encontrada nas parcelas 3 e 8; este fenómeno foi também observado por FerReIRA et al. (2008), noutras bacias hidrográficas ardidas em Portugal. Os autores avançam como possível explicação a infiltração e a transmissão da precipitação para a rede de drenagem através de redes de macroporos; uma explicação alternativa poderá ser dada pela presença de zonas saturadas nas proximidades do canal, onde uma parte significativa da escorrência 
seria gerada (p. ex. Soler et al., 2008). Conforme observado acima, a presença de maior humidade do solo em áreas de drenagem maiores (fig. 9), poderá indicar a ocorrência de geração de escorrência por saturação; a observação de escorrência de base na rede de drenagem, durante a maior parte do mês de Dezembro, é também indicadora da presença de água no solo com capacidade de movimento lateral subsuperficial, desde as encostas até aos canais. Seria interessante observar qual a relação entre escorrência em parcelas e no canal durante períodos de elevada repelência à água, o que se esperava que ocorresse durante o Verão e Outono de 2009. ravinas (e. g. Martinez-Casasnovas et al., 2003), o que não está contabilizado nas encostas analisadas neste estudo. No entanto, Shakesby e Doerr (2006) notam a reduzida observação de ravinas em áreas ardidas, o que tem levado alguns autores a assumirem a pouca importância deste fenómeno. A análise dos dados para outras encostas da área de estudo (fig. 2) poderá permitir uma melhor compreensão da importância das ravinas para a erosão da bacia hidrográficas, dado que duas ravinas foram instrumentadas com barreiras de sedimentos.
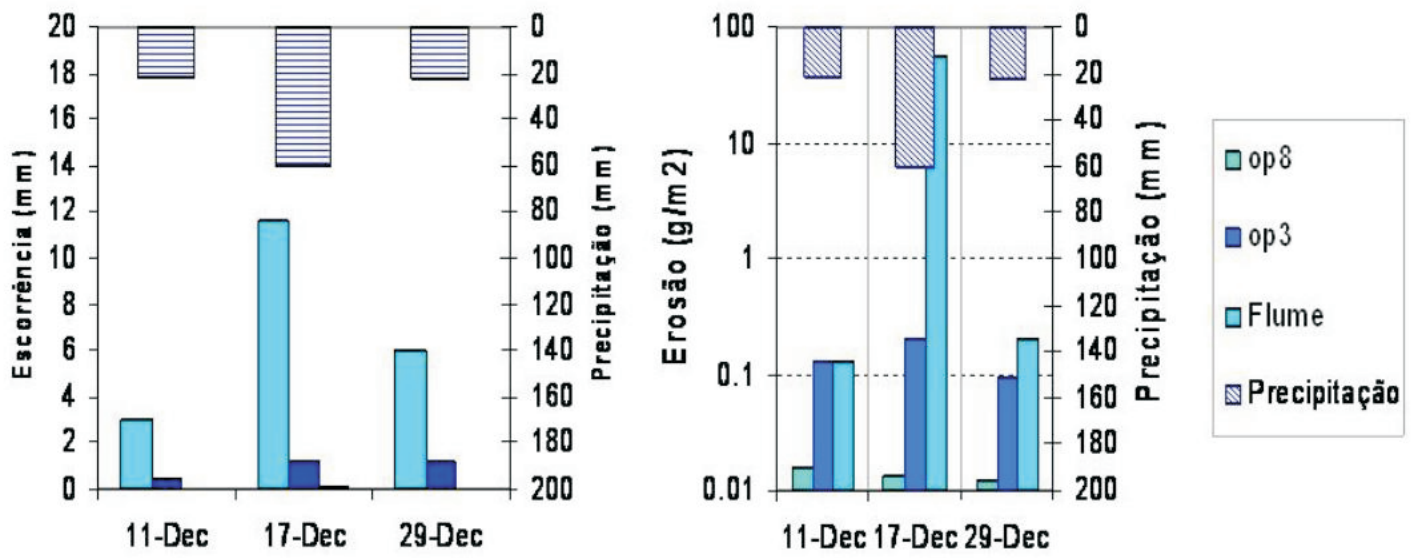

Fig. 10 - Escorrência nas parcelas 3 e 8, no canal hidráulico e precipitação em Dezembro (valores acumulados até à data indicada na figura).

Quanto à erosão do solo, os valores registados de 1 a 11 e de 18 a 29 de Dezembro são semelhantes entre a encosta das parcelas 3 (encosta mais longa) e o canal, sendo que a encosta das parcelas 8 (encosta mais curta) apresenta valores bastante inferiores (fig. 10), o que se deve provavelmente à escorrência mais reduzida. No entanto, de 12 a 17 de Dezembro, os valores registados no canal são bastante superiores aos registados à escala de encosta: cerca de $55 \mathrm{~g} / \mathrm{m}^{2}$, três ordens de grandeza superiores. Estes valores foram medidos quase exclusivamente durante um evento de precipitação, ocorrido a 13 de Dezembro. Este aumento de erosão poderá estar ligado a fenómenos ocorrendo principalmente na zona saturada da bacia hidrográfica (também observados por Soler et al., 2008, em bacias com escorrência por excesso de saturação); no entanto, GARCía-RuIz et al. (2008) notam que, nestes casos, a concentração de sedimentos tende a ser menor, devido à maior densidade de vegetação observada perto da rede de drenagem.

Outra explicação poderá ser avançada pelo facto dos fenómenos de precipitação mais fortes poderem levar a taxas de erosão bastante mais significativas em

\section{Discussão geral}

Os resultados obtidos nestes primeiros meses de monitorização evidenciam alguns fenómenos relatados por outros autores em áreas ardidas (e. g. SHAKEsby e DoerR, 2006; FerreIra et al., 2008), como a diminuição da erosão com o tempo, maior erosão à escala de micro parcelas do que à escala da encosta e maior escorrência à escala da bacia hidrográfica. Foram ainda observados fenómenos pouco estudados em bacias ardidas, mas observados noutras bacias, como a transição no comportamento de encostas curtas e longas entre períodos de elevada e baixa repelência, ou a importância da humidade do solo para a geração de escorrência à escala da bacia. Para estes últimos fenómenos será fundamental analisar os dados de escorrência e erosão recolhidos em outras encostas, bem como séries de dados auxiliares para coberto vegetal, repelência à água e outros parâmetros que ainda se encontram sob análise.

Uma análise preliminar dos resultados obtidos, conjuntamente com os de outros estudos no centro de Portugal, permite verificar que as taxas de escorrência e de erosão do solo são de ordem de grandeza similares às observadas em outras áreas; em particular, as taxas de 
erosão são bastante reduzidas, quando comparadas com o observado em áreas agrícolas. No entanto, conforme notado por SHAKESBY e DOERR (2006), este valor reduzido (e geralmente bastante superior ao observado em florestas não ardidas), poderá ainda assim ser importante para solos finos e degradados, como os que tipicamente se observam no centro de Portugal.

\section{Conclusões}

A implementação de uma rede de observação de escorrência e erosão a múltiplas escalas, numa micro bacia florestal ardida no centro de Portugal, permitiu obter indicações sobre a estrutura e a variabilidade dos processos hidrológicos e erosivos no espaço e no tempo. Os resultados preliminares indicam a possibilidade da evolução da conectividade espacial de água e sedimentos, levando a uma maior diferença na resposta hidrológica e erosiva entre o topo e as bases das encostas durante períodos mais húmidos. No entanto, é necessária ainda a aquisição de séries temporais mais longas, a análise de mais dados provenientes de outras encostas amostradas, e a recolha de dados auxiliares (indicadores da evolução do coberto vegetal e propriedades do solo), para permitir retirar conclusões deste estudo. No entanto, evidenciam-se as capacidades e a importância de observações a múltiplas escalas espaciais e temporais para a compreensão dos processos que ocorrem em áreas ardidas, bem como dos potenciais efeitos a jusante, como enxurradas e alterações da qualidade da água.

\section{Agradecimentos}

Este estudo foi realizado no âmbito do projecto EROSFIRE-II (PTDC/AGR-CFL/70968/2006), financiado pela Fundação para a Ciência e a Tecnologia (FCT) e cofinanciado pela FEDER através do programa POCI2010.

Agradecemos em particular a ajuda do Roel Toonen e Carli Mertopawiro do "Van Hall Larenstein, University of Applied Sciences" no trabalho de campo, e da Ana S.F. dos Santos no trabalho de laboratório.

\section{Bibliografia}

AndReu V.; Imeson A.C.; Rubio J.L. (2001) - "Temporal changes in soil aggregates and water erosion after a wildfire in a Mediterranean pine forest". Catena, 44: 69-84.

Boix-Fayos C.; Martínez-Mena, M.; Arnau-Rosalén, E.; CalvoCases A.; Castillo V.; Albaladejo J. (2006) - "Measuring soil erosion by field plots: Understanding the sources of variation". Earth-Science Reviews, 78: 267-285.
Cammeraat L.H. (2002) - "A review of two strongly contrasting geomorphological systems within the context of scale". Earth Surf. Process. Landforms, 27: 1201-1222.

Ferreira A.J.D.; Coelho C.O.A.; Ritsema C.J.; Boulet A.K.; KEIZER J.J. (2008) - "Soil and water degradation processes in burned areas: Lessons learned from a nested approach". Catena, 74: 273-285.

García-Ruiz J.M.; Regüés D.; Alvera B.; Lana-Renault N.; Serrano-Muela, P.; Nadal-Romero, E.; Navas A.; Latron J.; Martí-Bono C.; Arnáez J. (2008) "Flood generation and sediment transport in experimental catchments affected by land use changes in the central Pyrenees". Journal of Hydrology, 356: 245- 260.

Jung H.Y.; Hogue T.S., Rademacher L.K., Meixner T. (2009) - "Impact of wildfire on source water contributions in Devil Creek, CA: evidence from end-member mixing analysis. Hydrol. Process, 23: 183-200.

Keizer J.J.; Doerr S.H.; Malvar M.C.; Prats S.A.; Ferreira R.S.V.; Oñate M.G.; Coelho C.O.A.; Ferreira A.J.D. (2008) - "Temporal variation in topsoil water repellency in two recently burnt eucalypt stands in north-central Portugal”. Catena 74: 192-204.

Keizer J.J.; Malvar M.; Nunes J.P.; Silva J.S.; Coelho C.; Prats S.; Ferreira R.; Houmann M.; Lagewatrd M.; Ferreira A.; lucena J.; Pereira V.; Condesso de Melo T.; Afonso P.; Stolte J.; Jetten V. (2006) - "The role of land management practices in soil erosion hazard in eucalypt stands in north-central Portugal following forest wildfires". Forest Ecology and Management, 234S: S180-S207.

Kirkby M.; Bracken L.; Reaney, S. (2002) - "The influence of land use, soils and topography on the delivery of hillslope runoff to channels in SE Spain". Earth Surf. Process. Landforms, 27: 1459-1473.

Leighton-Boyce, G.; Doerr S.H.; Shakesby R.A.; Walsh R.P.D. (2007) - "Quantifying the impact of soil water repellency on overland flow generation and erosion: a new approach using rainfall simulation and wetting agent on in situ soil". Hydrol. Process, 21: 2337-2345

Lourenço, L. (2004a) - Risco de Erosão após Incêndios Florestais. Colecção Estudos (Estudos, 52), Colectâneas Cindínicas V. Núcleo de Investigação Cientifica de Incêndios Florestais e FLUC. 204 p. 
LoUREnço, L. (2004b) - "Evolução de vertentes e erosão dos solos, nas serras de xisto de centro de Portugal, em consequência de incêndios florestais. Análise de casos observados em 1987”. Em: Lourenço, L. (2004) - Risco de Erosão após Incêndios Florestais. Colecção Estudos (Estudos, 52), Colectâneas Cindínicas V. Núcleo de Investigação Cientifica de Incêndios Florestais e FLUC. 204 p.

Martínez-Casasnovas, J.A.; Antón-Fernández, C.; Ramos, M. C. (2003) - "Sediment production in large gullies of the Mediterranean area (NE Spain) from high-resolution digital elevation models and geographical information systems analysis". Earth Surf. Process. Landforms, 28: 443-456.

Parsons, A.J.; Brazier, R.E.; Wainwright, J.; Mark Powell, D. (2006) - "Scale relationships in hillslope runoff and erosion". Earth Surf. Process. Landforms, 31: 1384-1393.

Puigdefabregas, J.; del Barrio, G.; Boer, M.M.; Gutiérrez, L.; SolÉ, B. (1998) - "Differential responses of hillslope and channel elements to rainfall events in a semi-arid area". Geomorphology, 23: $337-351$.
Shakesby, R.A.; Coelho, C.O.A.; Ferreira, A.J.D.; Walsh, R.P.D. (2002) - “Ground-level changes after wildfire and ploughing in eucalyptus and pine forests, Portugal: implications for soil microtopographical development and soil longevity". Land Degrad. Develop., 13: 111-127.

ShAKesBy, R.A.; Doerr, S.H. (2006) - "Wildfire as a hydrological and geomorphological agent". Earth-Science Reviews, 74: 269-307.

Soler, M.; Latron, J.; Gallart, F. (2008) - "Relationships between suspended sediment concentrations and discharge in two small research basins in a mountainous Mediterranean area (Vallcebre, Eastern Pyrenees)". Geomorphology, 98: 143-152.

YAIR, A.; RAZ-YASSIF, N. (2004) - "Hydrological processes in a small arid catchment: scale effects of rainfall and slope length". Geomorphology, 61: 155-169. 